\title{
The tellurite-resistance determinants tehAtehB and klaAklaBtelB have different biochemical requirements
}

\author{
Raymond J. Turner, ${ }^{1,2}$ Joel H. Weiner ${ }^{2}$ and Diane E. Taylor ${ }^{1}$ \\ Author for correspondence: Diane E. Taylor. Tel: +1 403492 4777. Fax : +1 4034927521.
}

\footnotetext{
1 Dept of Medical Microbiology and Immunology, University of Alberta, Edmonton, Alberta, Canada T6G $2 \mathrm{H} 7$

2 Dept of Biochemistry. University of Alberta, Edmonton, Alberta, Canada T6G 2H7
}

\begin{abstract}
The tehAtehB operon from the Escherichia coli chromosome (32.3 min) mediates resistance to potassium tellurite $\left(\mathrm{K}_{2} \mathrm{TeO}_{3}\right)$ when expressed on a multicopy plasmid such as pUC8 (pTWT100). An MIC of $128 \mu \mathrm{g} \mathrm{ml}^{-1}$ is observed when tehAtehB is expressed in a wild-type host and grown on rich media. In this study, the tehAtehB determinant was transformed into mutants deficient in electron transport processes and/or thiol redox coupling within $E$. coli. These mutants included ubi, nad, cys, nar, trx, grx, gsh and sod. MICs of tehAtehB transformed into these mutants ranged from 1-16 $\mu \mathrm{g} \mathrm{K} \mathrm{TeO}_{3} \mathrm{ml}^{-1}$ compared to $0.03-2 \mu \mathrm{g} \mathrm{ml}^{-1}$ for strains transformed with a control plasmid. The telluriteresistance determinant locus kilA cloned from the IncP $\alpha$ plasmid RK2Ter (pDT1558) was also investigated in these strains. This tellurite-resistance determinant showed little or no dependency on the host genotype. The ability of tehAtehB to mediate resistance in wild-type hosts is limited to rich medium. Rich medium may provide a key unidentified cofactor required by TehATehB that is not provided under minimal conditions. Again, the ability of the kilA determinant to mediate tellurite resistance was independent of medium conditions. These data suggest that either a reducing environment or electronreducing equivalents are required for tehAtehB to mediate high levels of resistance to potassium tellurite. Therefore, the two resistance determinants studied here possess two very different biochemical mechanisms of resistance. Our data also suggest a mechanism for endogenous resistance to tellurite which involves nitrate reductase, superoxide dismutase, and thiol redox processes.
\end{abstract}

Keywords : tellurite resistance, glutathione, teh $A t e b B, k i l A$, thiol redox

\section{INTRODUCTION}

Tellurite $\left(\mathrm{TeO}_{3}^{2-}\right)$ is toxic to most micro-organisms, especially Gram-negative bacteria. Bacteria exposed to tellurite turn black as a result of internal deposition of elemental tellurium (Bradley et al., 1988; Lloyd-Jones et al., 1994; Taylor et al., 1988). The toxicity of tellurite has long been considered to be due to its oxidizing ability. However, the standard reduction potential of tellurite reduction is quite negative, $E_{\mathrm{m}^{\prime} 7}{ }^{*}=-1 \cdot 186 \mathrm{~V}$ for the reaction $\mathrm{TeO}_{3}^{2-}+3 \mathrm{H}_{2} \mathrm{O}+4 \mathrm{e}^{-} \leftrightarrow \mathrm{Te}^{0}+6 \mathrm{OH}^{-}$. Thus the specific mechanism of cellular oxidation and toxicity is unknown. Resistance to tellurite $\left(\mathrm{Te}^{\mathrm{r}}\right)$ is usually mediated by conjugative plasmids and the determinants encoded on these plasmids are usually highly specific for tellurite (Walter \& Taylor, 1992).
RK2 is a $60 \mathrm{~kb}$ plasmid of incompatibility group $\mathrm{P} \alpha$, which can be stably maintained in a broad range of Gramnegative bacteria (Thomas \& Smith, 1987). This plasmid encodes a network of co-regulated genes known as the kil-kor regulon (Figurski et al., 1982; Pansegrau et al., 1994). Within this regulon is a tellurite-resistance determinant which is normally cryptic or expressed at very low levels in wild-type RK2 (Bradley, 1985). The telluriteresistance determinant was mapped to the kil $A$ locus and was cloned into a pUC8 plasmid giving pDT1558 from a resistant variant of $\mathrm{RK} 2, \mathrm{RK} 2 \mathrm{Te}^{\mathrm{r}}$ (Walter \& Taylor, 1989). The operon comprises three genes, kla $A$, kla $B$ and $k l a C$, based on the gene designations of Pansegrau et al. (1994). The tellurite-resistant variant has been previously referred to as kil $A$, tel $A$ and telB (Turner et al., 1994a, b; Walter et al., 1991b), and all three genes were found to be 
necessary for resistance (Turner et al., 1994b). In order to maintain the designation between the $\mathrm{Te}^{\mathrm{r}}$ and $\mathrm{Te}^{\mathrm{s}}$ variants [which arises from a point mutation in klaC (Walter et al., 1991b)], the third gene of the $\mathrm{Te}^{\mathrm{r}}$ operon retains the original nomenclature of $t e l B$. Independent expression of each individual gene gives varying degrees of growth inhibition (Turner et al., 1994a) which is the phenotype originally associated with the operon. The genes encode polypeptides of $28 \mathrm{kDa}(\mathrm{KlaA}), 42 \mathrm{kDa}(\mathrm{KlaB})$ and a predicted integral membrane protein of $32 \mathrm{kDa}$ (TelB) (Walter et al., 1991a).

The operon tebAtebB specifies tellurite resistance when overexpressed (Walter \& Taylor, 1989; Walter et al., 1991b). The operon was originally cloned as a $6.8 \mathrm{~kb} \mathrm{Sall}$ fragment into pUC8, when cloning the resistance determinant from pHH1508a (Walter et al., 1991b). Subsequent analysis placed the two genes within a single operon located at 32.3 min on the E. coli chromosome (Taylor et al., 1994). These genes, teh $A$ and tebB, encode proteins of $36 \mathrm{kDa}$ (putative integral membrane protein) and $23 \mathrm{kDa}$, respectively (Walter et al., 1991b).

In the present study, the tellurite-resistance determinants kla $A$ klaBtelB and teh AtehB were transformed into various $E$. coli mutants deficient in electron transport processes and/or redox coupling in order to determine if their resistance mechanisms are coupled to these cellular processes.

\section{METHODS}

Bacterial strains and plasmids. $E$. coli strains used in this study were: JM83, AT2427, AT2455, DG37, JM246, JM457, JT14, NK1, RL165 and EC2254, provided by Dr B. Bachmann (E. coli Genetic Stock Center, Yale University School of Medicine, New Haven, CT, USA); AN59, AN120 (unc A401 argE3 thi-1 galK2 xyl-5 mtl-1 rpsL704), LE392 (F' supE44 supF58 bsdR514 galK2 galT22 metB1 trpR55 lacY1), RG51 (LE392 $\triangle$ uncB-uncD srl::Tn10 $\operatorname{rec} A 56$ ) and BPR100, provided by Dr B. Rosen (Wayne State University, Detroit, MI, USA); JF420, JF432, JF1070, JF2062, JF2200 and JF2201, provided by Dr J. Fuchs (University of Minnesota, St Paul, MN, USA); GR70N, GR71N and GR75N, provided by Dr R. B. Gennis (University of Illinois, Urbana, IL, USA); JHC1113, JHC1096 and JHC1078 provided by Dr T. Nunoshiba (Harvard School of Public Health, New Haven, CT, USA); LCB2048, provided by Dr G. Giordano (Laboratoire de Chimie Bacterienne, CNRS,

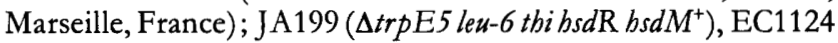
(JA199 cysI) and plasmid pJYW2, which overexpresses Cys JIH (sulfite reductase), and pJRS102, which overexpresses CysG JIH (sulfite reductase with excess sirohaem synthesis) (Wu et al., 1991), provided by Dr N. M. Kredich (Duke University Durham, NC, USA); QC4468, QC1712, QC1725 and QC1799 as well as plasmids pDT1-5 which overexpress $\operatorname{sod} A$ (Touati, 1983) and pHS1-8 expressing sodB (Carlioz et al., 1988) were obtained from Dr D. Touati (Institut Jacques Monod, CNRS, Paris, France). Other E. coli strains used in this study were $\mathrm{HB} 101\left[\mathrm{~F}^{\prime}\right.$ bsdS20 $\left(\mathrm{r}_{\mathrm{B}}^{-} \mathrm{m}_{\mathrm{B}}^{-}\right)$leu sup E44 ara-14 galK2 lac Y1 pro $A 2$ rpsL20 xyl-5 mtl-1 rec $A 13 \mathrm{mcrB}$ ] (Boyer \& Roulland-Dussoix, 1969) and MC4100 (Casadaban, 1976). The genotypes of the different strains not listed here are reported in Tables 1-6.

The tellurite-resistance plasmids used in this study include pTWT100 which contains the teh AtebB as the $3.3 \mathrm{~kb}$ fragment from pDT1364 (Taylor et al., 1994; Turner et al., 1995).
pDT1364 is the original pUC8-based clone of a $6.8 \mathrm{~kb}$ fragment from the E. coli chromosome containing teb AtebB (Walter $e t$ al., $1991 \mathrm{~b})$. pRT6 is the same as pD'T1364 with the ampicillinresistance marker replaced with a kanamycin-resistance cassette from pKIXX (Pharmacia). pDT1558 contains the kla AklaBtelB operon from the IncP $\alpha$ plasmid $\mathrm{RK}_{2} \mathrm{Te}^{\mathrm{r}}$ cloned into $\mathrm{pUC} 8$ (Walter et al., 1991a). Similarly, pRT4 is pDT1558 with the kanamycin cassette. The derivatives $\mathrm{pRT} 4$ and $\mathrm{PRT} 6$ were used in the cases where the strain tested contained an ampicillinresistance marker.

Growth conditions. All overnight bacterial cultures were grown in Luria-Bertani (LB) broth (Sambrook et al., 1989). Experiments with minimal media used Min A broth (Miller, 1992) supplemented with thiamine and the required amino acids based on the strain genotype. Carbon sources were added to a final concentration of $2 \%(\mathrm{w} / \mathrm{v})$. All media experiments were performed in 1-2 ml total volume in a $30 \mathrm{ml}$ culture tube, and were incubated at $37^{\circ} \mathrm{C}$ in a shaker bath. Antibiotics were used at the following concentrations: ampicillin $\left(100 \mu \mathrm{g} \mathrm{m}^{-1}\right)$, chloramphenicol $\left(30 \mu \mathrm{g} \mathrm{ml}^{-1}\right)$, kanamycin sulfate $\left(42 \mu \mathrm{g} \mathrm{ml}^{-1}\right)$ and tetracycline $\left(12.5 \mu \mathrm{g} \mathrm{ml}^{-1}\right)$.

MIC determinations. For MIC determination, overnight cultures grown in LB broth were diluted $10^{4}$ in Penassay broth or LB broth and 10-25 $\mu$ l aliquots were dropped onto medium plates containing serial dilutions of potassium tellurite (Sigma). Bacterial growth media used included Brain Heart Infusion (Oxoid), LB (Becton Dickinson), and Mueller-Hinton (Oxoid). The most reproducible and consistent data was obtained using LB agar and it is with this medium that the MIC values are reported in Tables 1-6. All reported MIC values are the result of at least three independent determinations. If variability of the MIC was observed, the ranges are reported. All MIC determinations were performed under aerobic growth conditions.

\section{RESULTS}

Plasmids containing the tehAtebB and klaAklaBtelB determinants were transformed into a variety of mutants with important roles in the maintenance of thiol redox balance and electron transport. These recombinant cultures were assessed for their ability to mediate resistance to tellurite (Tables 1-6). The determinant teh AtebB in the pUC8 vector (pTWT100) results in a culture with an MIC of $128-256 \mu \mathrm{g} \mathrm{m}^{-1}$, and the klaAklaBtelB operon gives an MIC of $256 \mu \mathrm{g} \mathrm{m}^{-1}$ in pUC8 (pDT1558) when harboured in wild-type E. coli strains (Taylor et al., 1994; Turner et al., 1994b; Walter \& Taylor, 1989). In some experiments, pDT1555, a pACYC184-based clone of kla AklaBtelB, was also utilized and gave the same or higher MICs as $\mathrm{pDT} 1558$. This was expected since reduced expression of kla AklaBtelB gives higher MIC values resulting from a reduced-lethality phenotype (Turner et al., 1994b).

\section{Importance of cysteine, ubiquinone and nicotinamide biosynthesis}

When plasmids containing the teb AtebB determinant were transformed into mutants in the cysteine (Table 1), ubiquinone (Table 2) or nicotinamide (Table 3) metabolic pathways, the resistance to tellurite was severely depressed. Tellurite MICs in these strains transformed with 
Table 1. Effect of determinants on tellurite MICs in strains of E. coli deficient in cysteine metabolism (cys)

\begin{tabular}{|c|c|c|c|c|c|}
\hline \multirow[t]{2}{*}{ Strain } & \multirow[t]{2}{*}{ Genotype } & \multirow{2}{*}{$\begin{array}{l}\text { Description of relevant } \\
\text { genotype }\end{array}$} & \multicolumn{3}{|c|}{ MIC of tellurite $\left(\mu \mathrm{g} \mathrm{ml}^{-1}\right)$ with plasmids: } \\
\hline & & & $\begin{array}{c}\text { pUC8 } \\
\text { (Control) }\end{array}$ & $\begin{array}{c}\text { pTWT100 } \\
(\text { tehAtehB) }\end{array}$ & $\begin{array}{c}\text { pDT1558 } \\
\text { (klaAklaBtelB) }\end{array}$ \\
\hline JM83 & $\Delta$ lac-pro $\phi 80$ dlacZ $\Delta \mathrm{M} 15$ rpsL & Wild-type & 2 & $128-256$ & 256 \\
\hline AT2427 & $\begin{array}{l}\mathrm{F}^{-} \text {cysJ43 relA1 spoT1 thi-1 } \\
\text { phoM510 } \lambda^{-}\end{array}$ & Sulfite reductase $\beta$ & 2 & 4 & 256 \\
\hline AT2455 & $\begin{array}{l}\text { Hfr thi-1 cysG44 mal-18 relA1 } \lambda^{-} \\
\text {spoT1 }\end{array}$ & Sirohaem synthesis & 2 & 4 & 256 \\
\hline DG37 & Hfr $\operatorname{rel} A 1 \Delta(p t s-c y s A) 127$ spoT1 & $\begin{array}{l}\text { Sulfate permease and } O \text { - } \\
\text { acetylserine sulfhydrylase B }\end{array}$ & 2 & 4 & 256 \\
\hline EC2254 & $\begin{array}{l}\text { araD139 } \Delta \text { lacU169 thi trp rpsL relA } \\
\text { cys362:: mud1:: (Ap lac })\end{array}$ & $\begin{array}{l}\text { Sulfite reductase } \alpha \text { and } \beta \text {, } \\
\text { adenylsulfate reductase }\end{array}$ & 2 & 8 & 256 \\
\hline JM246 & $\mathrm{F}^{-}$cysI53 $\lambda^{-} \Omega(r r n D-r r n E) 1$ & Sulfite reductase $\alpha$ & 2 & 2 & 256 \\
\hline JM457 & $\begin{array}{c}\mathrm{F}^{-} \text {pro-50 bis-97 fpk-1 cysI53 cysE51 } \\
\text { metB1 lac galT47 mtl str } A 192 \text { ts } x\end{array}$ & $\begin{array}{l}\text { Sulfite reductase } \alpha \text {, serine } \\
\text { acetyltransferase }\end{array}$ & 2 & 4 & 256 \\
\hline JT14 & cysB214 trpE9829 pyrF & Positive regulator & $1-2$ & 2 & 256 \\
\hline NK1 & $\operatorname{trp}$ E5 leu-6 thi cysB rbs ${ }^{+} \mathrm{r}^{-} \mathrm{m}^{+}$ & Positive regulator & $1-2$ & 4 & ND \\
\hline RL165 & $\begin{array}{l}\text { thr-1 leuB6 trp-1 bis-61 cysK } 511 \\
\text { argH1 thi-1 lacY1 gal-6 xyl-7 } \\
\text { mal } A 1\left(l^{R}\right) \text { mtl-2 rpsL9 ton } A 2 \\
\text { supE44 } \lambda^{-}\end{array}$ & $\begin{array}{l}\text { O-Acetylserine sulfhydrylase } \\
\text { A }\end{array}$ & 2 & 8 & 256 \\
\hline
\end{tabular}

ND, Not determined.

Table 2. Effect of determinants on tellurite MICs in strains of $E$. coli deficient in ubiquinone metabolism ( $u b i$ )

\begin{tabular}{|c|c|c|c|c|c|}
\hline \multirow[t]{2}{*}{ Strain } & \multirow[t]{2}{*}{ Genotype } & \multirow{2}{*}{$\begin{array}{l}\text { Description of relevant } \\
\text { genotype }\end{array}$} & \multicolumn{3}{|c|}{ MIC of tellurite ( $\left.\mu \mathrm{g} \mathrm{ml}^{-1}\right)$ with plasmids: } \\
\hline & & & $\begin{array}{c}\text { pUC8 } \\
\text { (Control) }\end{array}$ & $\begin{array}{l}\text { pTWT100 } \\
\text { (tehAtehB) }\end{array}$ & $\begin{array}{c}\text { pDT1558 } \\
\text { (klaAklaBtelB) }\end{array}$ \\
\hline JM83 & $\Delta$ lac-pro $\phi 80$ dlacZ $\Delta \mathrm{M} 15$ rpsL & Wild-type & 2 & $128-256$ & 256 \\
\hline AN59 & $\begin{array}{l}\text { thr-1 leuB6 ubiB352 thi-1 lacZ4 } \\
\text { rpsL8 supE44 }\end{array}$ & $\begin{array}{l}\text { 2-Octaprenylphenol } \rightarrow 2 \text { - } \\
\text { octaprenyl-6-methoxyphenol }\end{array}$ & 2 & 4 & 128 \\
\hline AN66 & $\begin{array}{l}\text { thr-1 leuB6 ubiD410 lacZ4 rpsL8 } \\
(p 1)^{+} \text {supE44 }\end{array}$ & $\begin{array}{l}\text { 3-Octaprenyl-4- } \\
\text { hydroxybenzoate } \rightarrow 2 \text { - } \\
\text { octaprenylphenol }\end{array}$ & 2 & 1 & 256 \\
\hline JF496 & $\begin{array}{l}\text { asnB } 50:: \operatorname{Tn} 5 \text { ubiF411 nagB2 relA1 } \\
\text { spoT1 bglR13 asn } A 31 \text { rbs-4 metB1 }\end{array}$ & $\begin{array}{l}\text { 2-Octaprenyl-3-methyl-6- } \\
\text { methoxy-1,4-benzoquinone } \\
\rightarrow \text { 2-octaprenyl-3-methyl-3- } \\
\text { methyl-5-hydroxy-6- } \\
\text { methoxy-1,4-benzoquinone }\end{array}$ & 2 & 4 & 256 \\
\hline
\end{tabular}

pTWT100 ranged from 0.5 to $8 \mu \mathrm{g} \mathrm{ml}^{-1}$. Little or no effect was observed for the MICs that the klaAklaBtelB determinant was able to mediate in these strains. MICs of $1-2 \mu \mathrm{g} \mathrm{K}_{2} \mathrm{TeO}_{3} \mathrm{ml}^{-1}$ were observed in these strains carrying the control plasmid pUC8. These results suggest that the products of these metabolic pathways are utilized in some manner by the teb AtebB determinant.

In some of the specific mutants more than one strain was utilized because we were not able to obtain the appropriate isogenic wild-type strains. Additionally, not all mutants were stable and the possibility of selection of revertants during the experiment which might then contaminate the cultures was a concern. Therefore, utilizing many mutants alleviated these difficulties.

Other energetics mutant strains which were studied included unc ( $\mathrm{F}_{1} \mathrm{~F}_{0}$-ATPase). No effects on wild-type MICs were observed in this type of host, with or without a resistance determinant. 
Table 3. Effect of determinants on tellurite MICs in strains of $E$. coli deficient in nicotinamide metabolism (nad)



Table 4. Effect of determinants on tellurite MICs in strains of $E$. coli deficient in thiol redox enzymes and metabolites

\begin{tabular}{|c|c|c|c|c|c|}
\hline \multirow[t]{2}{*}{ Strain } & \multirow[t]{2}{*}{ Genotype } & \multirow{2}{*}{$\begin{array}{l}\text { Description of relevart } \\
\text { genotype }\end{array}$} & \multicolumn{3}{|c|}{ MIC of tellurite ( $\mu \mathrm{g} \mathrm{ml}^{-1}$ ) with plasmids: } \\
\hline & & & $\begin{array}{c}\text { pUC8 } \\
\text { (Control) }\end{array}$ & $\begin{array}{c}\text { pTWT100 } \\
(\text { tehAtehB) }\end{array}$ & $\begin{array}{c}\text { pDT1558 } \\
\text { (klaAklaBtelB) }\end{array}$ \\
\hline JF1070 & AB1157*; pro $A B$ lacIPOZY $A$ & Wild-type & 2 & 256 & 256 \\
\hline JF2062 & $\mathrm{JF} 1070 ; \operatorname{tr} \times A:: \mathrm{kan}$ & Thioredoxin & $0 \cdot 5-1$ & 8 & 256 \\
\hline JF420 & JF1070; gor-1 & Glutathione oxidoreductase & $0 \cdot 25$ & 4 & 256 \\
\hline JF2200 & $\mathrm{JF} 1070 ; g s h A:$ kan & Glutathione synthetase A & $0 \cdot 25$ & 4 & 256 \\
\hline JF2201 & $\mathrm{JF} 1070 ; g s h B:: \mathrm{kan}$ & Glutathione synthetase B & $0 \cdot 25$ & 4 & 256 \\
\hline
\end{tabular}

* AB1157: $\mathrm{F}^{-}$thr-1 leuB6 lacY1 supE44 rfbD1 thi-1 malT1 ara-14 galK2 xyl-5 mtl-1 mgl-51 hisG4 (gpt-pro)62 kdgK51 argE3 tsx-33.

\section{Importance of thiol redox balance components}

Mutants in thiol redox, carrying the control plasmid, displayed hypersensitivity to tellurite, with MIC values ranging from $0 \cdot 25$ to $1 \mu \mathrm{g} \mathrm{ml}^{-1}$ (Table 4 ). When these mutants were transformed with the plasmids carrying tehAtehB, MICs ranged from 2 to $8 \mu \mathrm{g} \mathrm{ml}^{-1}$ compared to $128-256 \mu \mathrm{g} \mathrm{ml}^{-1}$ for the wild-type. Again, no effect was observed on the ability of the klaAklaBtelB operon to mediate resistance in these strains.

The results in Table 4 suggested that thiol redox is involved both in host resistance and teh AtebB-mediated tellurite resistance. To test if glutathione is involved in the resistance mechanism of tebAtebB, glutathione inhibitors were employed. Buthione sulfoximine (BSO), an inhibitor of $\gamma$-glutamylcysteine synthetase $(g s h A)$, was added to cultures at a concentration of $10 \mathrm{mM}$. This concentration would be expected to eliminate all glutathione synthesis (Griffith \& Meister, 1979). A scavenger of glutathione and free cysteine, diethylmaleate (DEM), was also utilized, at a concentration of $5 \mathrm{mM}$. Wild-type host strains exposed to these compounds had a reduction of their MIC from 2 to $1 \mu \mathrm{g} \mathrm{ml}^{-1}$. No effect on the MIC with HB101 (pDT1558) was observed. However, the MIC with HB101(pDT1364) or HB101(pTWT100) decreased from
128 to $64 \mu \mathrm{g} \mathrm{ml}^{-1}$ in the presence of BSO and down to $1 \mu \mathrm{g} \mathrm{ml} \mathrm{m}^{-1}$ in the presence of DEM. The failure of BSO to have a significantly large effect on $E$. coli glutathione concentration has been reported by others (Moore et al., 1989; Romero \& Canada, 1991). Consistent with these previous findings, we also only observed a minor effect, but the results with the scavenger DEM confirm the mutant data, suggesting that glutathione is involved both in the host resistance as well as with the resistance mediated by teh AtebB.

\section{Importance of nitrate and sulfite reductases}

Recent studies by $\mathrm{C}$. Avazeri and co-workers have shown that nitrate reductase (NarG) has a tellurite reductase activity (unpublished). Additionally, overexpression of the nar $G$ operon behind an inducible tac promoter gives rise to low levels of tellurite resistance under aerobic conditions (C. Avazeri and others, unpublished). We tested whether overexpression of sulfite reductase had similar properties, or if this enzyme would modulate tellurite resistance in the presence or absence of overexpressed tebAtebB or klaAklaBtelB. The wild-type JA199 or cysI (EC1124) hosts harbouring pJRS102 (which overexpresses cysGJIH) gave tellurite MICs in the range of 
Table 5. Effect of determinants on tellurite MICs in strains of E. coli deficient in nitrate reductase

\begin{tabular}{|c|c|c|c|c|c|}
\hline \multirow[t]{2}{*}{ Strain } & \multirow[t]{2}{*}{ Genotype } & \multirow{2}{*}{$\begin{array}{c}\text { Description of relevant } \\
\text { genotype }\end{array}$} & \multicolumn{3}{|c|}{ MIC of tellurite $\left(\mu \mathrm{g} \mathrm{ml}^{-1}\right)$ with plasmids: } \\
\hline & & & $\begin{array}{c}\text { pUC8 } \\
\text { (Control) }\end{array}$ & $\begin{array}{c}\text { pTWT100 } \\
(\text { tehAtehB })\end{array}$ & $\begin{array}{c}\text { pDT1558 } \\
\text { (klaAklaBtelB) }\end{array}$ \\
\hline MC4100 & $\begin{array}{l}\mathrm{F}^{-} \text {araD139 } \Delta(\operatorname{argR}-l a c) \mathrm{U} 169 \\
\text { ftbB5301 ptsF25 relA1 rpsL150 } \\
\text { deoC1 rpsR }\end{array}$ & Wild-type & 2 & $128-256$ & $256-512$ \\
\hline LCB2048 & $\begin{array}{c}\text { thi-1 thr-1 leu6 lacY1 supE44 rpsL } \\
\Delta \text { nar-25(narG-narH) narZ:: } \Omega\end{array}$ & $\begin{array}{l}\text { Nitrate reductases (NarGHJI } \\
\text { and NarZYWV) }\end{array}$ & $0 \cdot 015-0 \cdot 03$ & 16 & 64 \\
\hline
\end{tabular}

Table 6. Effect of determinants on tellurite MICs in strains of $E$. coli deficient in antistress response

\begin{tabular}{|c|c|c|c|c|c|}
\hline \multirow[t]{2}{*}{ Strain } & \multirow[t]{2}{*}{ Genotype } & \multirow{2}{*}{$\begin{array}{l}\text { Description of relevant } \\
\text { genotype }\end{array}$} & \multicolumn{3}{|c|}{ MIC of tellurite ( $\left.\mu \mathrm{g} \mathrm{ml}^{-1}\right)$ with plasmids: } \\
\hline & & & $\begin{array}{c}\text { pUC8 } \\
\text { (Control) }\end{array}$ & $\begin{array}{c}\text { pTWT100 } \\
\text { (tehAtehB) }\end{array}$ & $\begin{array}{c}\text { pDT1558 } \\
\text { (klaAklaBtelB) }\end{array}$ \\
\hline QC4468 & $\mathrm{F}^{-} \Delta($ lac $) \mathrm{U} 169 r p s L$ & Wild-type & 2 & 128 & 256 \\
\hline QC1712 & $\begin{array}{l}\text { QC4468; } \Delta \text { sod } A 3 r b u:: \operatorname{Tn} 5 \\
\text { zdb::Tn } 10\end{array}$ & Superoxide dismutase $[\mathrm{Mn}]$ & $0 \cdot 125-0.25$ & 128 & 128 \\
\hline QC1725 & QC4468; $\Delta$ sod $A 3 z d b::$ mini-tet & Superoxide dismutase $[\mathrm{Mn}]$ & $0.125-0.25$ & $128-256$ & 256 \\
\hline QC1799 & $\mathrm{QC} 4468 ; \Delta \operatorname{sod} A 3 \Delta \mathrm{s} o d B 2$ & $\begin{array}{l}\text { Superoxide dismutases }[\mathrm{Mn}] \\
\text { and }[\mathrm{Fe}]\end{array}$ & $0 \cdot 125-0 \cdot 25$ & 128 & 128 \\
\hline $\mathrm{JHC1113}$ & QC4468; marR1 xdd-2207:: Tn10 & $\begin{array}{l}\text { Repressor multi-antibiotic } \\
\text { resistance }\end{array}$ & 4 & 256 & 256 \\
\hline JHC1096 & 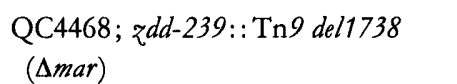 & Deletion in MarRAB & $2-4$ & 256 & 256 \\
\hline $\mathrm{JHC1078}$ & QC4468; soxR105 zjc-2204:: $\operatorname{Tn} 10$ & $\begin{array}{l}\text { Repressor of redox stress } \\
\text { response }\end{array}$ & 4 & 256 & 256 \\
\hline
\end{tabular}

$2-4 \mu \mathrm{g} \mathrm{ml}^{-1}$. No $\mathrm{TeO}_{3}^{2-} \rightarrow \mathrm{Te}^{0}$ activity was observed in cell-free extracts of JA199(pUC8), JA199(pJRS102) or JA199(pJYW2) using a qualitative aerobic assay (assessed by blackening of the extract/culture as measured by $\left.\Delta A_{600}\right)$. Hosts harbouring both pJRS102 and pRT6 (teh AtehB clone) or pRT4 (kla AklaBtelB clone) had MICs of 128 and $256 \mu \mathrm{g} \mathrm{ml}^{-1}$, respectively. These results suggest that sulfite reductase alone does not interact with tellurite directly and does not enhance the activity of both resistance determinants. However, the absence of sulfite reductase is detrimental to the ability of the teh $A t e b B$ determinant to mediate resistance (Table 1).

Tellurite resistance of nitrate reductase mutants is severely depressed, with MICs of $0.015-0.03 \mu \mathrm{g} \mathrm{ml}^{-1}$ (Table 5). The resistance level for the teb $A t e b B$ determinant was lowered in this host but not to the same extent as with other mutants studied. However, unlike the other mutants tested, the tellurite resistance mediated by the klaAklaBtelB determinant was also reduced in nitrate reductase mutants.

\section{Importance of oxidative stress response}

We also investigated the MICs of tellurite in mutants linked to oxidative stress (Table 6). Superoxide dismutase mutants were hypersensitive to tellurite, with MICs ranging from $0 \cdot 125$ to $0 \cdot 25 \mu \mathrm{g} \mathrm{ml}^{-1}$. Little or no effect was observed on the MICs of the tellurite-resistance determinants in hosts lacking either or both superoxide dismutases (SodA, SodB). Additionally, overexpression of SodA did not give rise to enhanced resistance to tellurite compared to the wild-type host.

Mutants unable to elicit a stress response (sox or mar) (Ariza et al., 1994) were also tested. As these proteins regulate a large number of genes, we considered it possible that one of them may be vital to the resistance mechanism mediated by the two tellurite-resistance determinants. However, as seen by the data in Table 6, this was not the case. The MICs for the determinants were comparable to the wild-type or slightly increased.

\section{Effect of media conditions}

The effect of stress from medium conditions was also assessed based on the ability of the determinants to facilitate growth in the presence of $25 \mu \mathrm{g} \mathrm{K}_{2} \mathrm{TeO}_{3} \mathrm{ml}^{-1}$ using the wild-type host HB101 (Table 7). This concentration is well below the MIC and in rich media both resistance determinants allow the host to grow to normal cell densities. However, when only a minimal salts 
Table 7. Dependency on medium conditions for the tellurite-resistance determinants to confer resistance to $25 \mu \mathrm{g} \mathrm{K}_{2} \mathrm{TeO}_{3} \mathrm{ml}^{-1}$

- , No growth;,,++++++ , increasing amounts of growth; $\sim$, observed darkening of the broth as a result of $\mathrm{TeO}_{3}^{2-} \rightarrow \mathrm{Te}^{0}$ reduction but little or no viable cells present.

\begin{tabular}{|c|c|c|c|}
\hline \multirow[t]{2}{*}{ Medium } & \multicolumn{3}{|c|}{ Plasmid } \\
\hline & $\begin{array}{c}\text { pUC8 } \\
\text { (Control) }\end{array}$ & $\begin{array}{c}\text { pTWT100 } \\
(\text { tehAtehB) }\end{array}$ & $\begin{array}{c}\text { pDT1558 } \\
\text { (klaAklaBtelB) }\end{array}$ \\
\hline Luria-Bertani broth & - & +++ & +++ \\
\hline Terrific Broth & - & +++ & +++ \\
\hline Mueller-Hinton & - & +++ & +++ \\
\hline $\operatorname{Min} \mathrm{A}+$ glucose & - & - & +++ \\
\hline Min A + glycerol & - & - & ++ \\
\hline $\operatorname{Min} A+$ succinate & - & - & + \\
\hline Min A + lactate & - & $\sim$ & ++ \\
\hline Min A + glycerol + fumarate & - & - & ++ \\
\hline Min A + glycerol + DMSO & - & - & ++ \\
\hline Peptone + glucose + fumarate & - & ++ & ++ \\
\hline $\operatorname{Min} A+$ glucose $+1 \%$ yeast extract & - & ++ & ++ \\
\hline Min $A+$ glucose $+1 \%$ tryptone & - & ++ & ++ \\
\hline Min $A+$ glucose $+1 \%$ Casamino acids & - & + & ++ \\
\hline Min $A+$ glucose $+0 \cdot 1 \%$ cystine & - & $\sim$ & ++ \\
\hline Min $A+$ glucose $+0 \cdot 1 \%$ oxidized glutathione & - & $\sim$ & ++ \\
\hline Min A + glucose + $10 \mathrm{mM} \mathrm{L-2-oxothiazolidine}$ & - & + & +++ \\
\hline
\end{tabular}

medium was utilized with a single carbon source, the determinant tehAtehB did not protect the host from tellurite. In contrast, the klaAklaBtelB determinant was able to protect the host under all medium conditions studied. Because the addition of tryptone or Casamino acids was able to restore growth for hosts harbouring teh AtehB, it is possible that the missing factor supplied by the medium is an amino acid or a peptide. These medium components do not act on tellurite to reduce its effective concentration (Turner et al., 1992b). Based on the mutant data, we suggest that this may be a cysteine-based peptide, possibly glutathione. Unfortunately, the addition of reduced thiol (cysteine or glutathione-SH) causes direct reduction of the tellurite to elemental tellurium and could not be tested. Addition of excess amounts of the oxidized forms (cystine and glutathione-S-S-glutathione), showed some $\mathrm{TeO}_{3}^{2-} \rightarrow \mathrm{Te}^{0}$ reduction with only a trace amount of growth. Furthermore, addition of L-2-oxothiazolodine, which has been shown to increase intracellular glutathione-SH levels (Romero \& Canada, 1991), was able to restore some growth.

\section{DISCUSSION}

A number of possible mechanisms can be evoked to explain tellurite resistance. These include reduced uptake and increased efflux, detoxification through reduction or chemical modification, sequestration, repair of cellular damage, production of a compensating enzyme, modification of the target of toxicity, regulation of host genes, and modification of host enzymic function and/or specificity. We have ruled out increased efflux and/or reduced uptake as a mode of resistance for both the klaAklaBtelB and tehAtebB tellurite-resistance determinants based on tellurite accumulation studies (Turner et al., 1995). However, the precise biochemical mechanism has yet to be identified for these tellurite-resistance determinants.

In the present study we have addressed the metabolic state of the host necessary for the tellurite-resistance determinants to mediate resistance. We have found that the teh AtehB determinant is dependent almost exclusively on the host cell to provide a particular metabolic state. Resistance mediated by the teh AtebB determinant requires a functional electron transport chain with a functional quinone pool. Additionally, a cysteine metabolic pathway is required, probably for the synthesis of glutathione which was also found to be required. Other thiol redox metabolites were also found to be required for teh $A$ tebB to mediate full resistance. In contrast, the klaAklaBtelB tellurite-resistance determinant required none of these host systems. It is clearly evident from these studies that the tellurite-resistance determinants teh AtehB and klaAklaBtelB have two very different biochemical mechanisms. Additionally, there appears to be a synergy between the hosts resistance mechanisms and that of tehAtebB.

Two other tellurite-resistance determinants have been identified. The ter determinant from the IncHI2 plasmid also mediates tellurite resistance (Hill et al., 1993; LloydJones et al., 1994). Although the mechanism of resistance has not been determined for this system, reduced uptake and/or efflux has been ruled out (Lloyd-Jones et al., 1994; 
Turner et al., 1995). Clones of the ter determinant from both the pMER610 and R478 plasmids have been transformed into some of the mutant strains studied here (unpublished results). These preliminary results suggest that the biochemical resistance mechanism of the ter determinant is different from that of the teh AtebB and kla AklaBtelB determinants described in the present paper. Additionally, the oxyanion efflux pump ars $A B C$ from the FI plasmid has been shown to mediate moderate levels of resistance towards tellurite (Turner $e t$ al., 1992a). There are also a variety of organisms which have demonstrated reduction of inorganic oxyanions including $\mathrm{TeO}_{3}^{2-}$ (reviewed by Turner et al., 1995, and Walter \& Taylor, 1992). The data suggests that there may be as many as five distinct mechanisms of tellurite resistance.

The MarRAB and SoxRAB responses regulate a large number of genes (Ariza et al., 1994; Rosner \& Slonczewski, 1994). We tested the hypothesis that the stress of exposure to tellurite may induce such a response. However, this was not observed in our experiments.

Results from the minimal medium experiments suggest two possibilities: (i) the increased stress of growing under minimal medium conditions is beyond the energetic capabilities for the tehAtebB determinant; (ii) there is a requirement in the growth medium for a factor, possibly amino acid/peptide-based, that either acts on tellurite to bring it to the cell in a less toxic form or acts as a cofactor to TehATehB.

Our study also provides information on the host's mechanism of processing tellurite. Cultures of E. coli without a resistance determinant will turn black upon exposure to tellurite as a result of tellurium deposition. Most of the mutant strains studied have an MIC between 1 and $2 \mu \mathrm{g} \mathrm{ml}^{-1}$ without any plasmid or when harbouring a control plasmid pUC8. However, a strain with nitrate reductases mutations (nar $G$ and nar $Z$ ) showed a marked hypersensitivity to tellurite with an MIC of $0.03 \mu \mathrm{g} \mathrm{ml}^{-1}$. This suggests that the membrane-bound nitrate reductase may be the primary defence of the cell against tellurite in agreement with the observations of $C$. A vazeri and others (unpublished). Mutants in the thiol redox coupling activity in the cell had reduced MICs, from 0.25 to $0.5 \mu \mathrm{g} \mathrm{ml}^{-1}$, indicating that these thiol agents are also used by $E$. coli as a defence against tellurite. Glutathione has been implicated in the resistance of other heavy metals in E. coli including arsenate (Oden et al., 1994) and cisplatinum (Salles \& Calsou, 1992) resistance. Defects in glutathione synthesis in many micro-organisms result in increased susceptibility to a variety of heavy metals including cadmium, mercury, copper, lead, zinc, bismuth and silver (Penninckx \& Elskens, 1993). Selenite $\left(\mathrm{SeO}_{3}^{2-}\right)$ reacts with glutathione-SH to give Glt-S-Se-S-Glt which is then acted on by glutathione reductase to give oxidized glutathione and $\mathrm{Se}^{\mathbf{0}}$ (Ganther, 1971). Although the chemistry of selenium and tellurium is slightly different, it is still possible that this activity occurs to some extent in E. coli. Since $\mathrm{TeO}_{3}^{2-}$ reacts readily with free thiols, other targets in the cell for tellurite attack could include $\mathrm{CoA}-\mathrm{SH}$ and lipoamide dehydrogenase. We have further experiments underway to test this hypothesis.
Hypersensitivity was also observed in sod hosts with MICs in the $0 \cdot 125-0 \cdot 25 \mu \mathrm{g} \mathrm{ml}^{-1}$ range. This sensitivity may be an indication that $\mathrm{O}_{2}^{-}$is produced as a by-product of the $\mathrm{TeO}_{3}^{2-} \rightarrow \mathrm{Te}^{0}$ reduction within the cell. Metabolic superoxide production is considered to be due to leakage of electrons from the respiratory chain dehydrogenases (Imlay \& Fridovich, 1991). It is possible that the tellurite reduction activity catalysed by nitrate reductase produces excessive amounts of $\mathrm{O}_{2}^{-}$.

Further protection can be afforded by defects in phosphate transport which can mediate low levels of resistance to tellurite (Tomas \& Kay, 1986). Thus we can envisage a model in which tellurite enters the cell by the phosphate uptake system and is acted on at the cytoplasmic side of the inner membrane by nitrate reductase. Tellurite which circumvents this line of defence is then acted on by glutathione and other reduced thiols in the cytoplasm which would give rise to further $\mathrm{TeO}_{3}^{2-} \rightarrow \mathrm{Te}^{0}$ reduction. Superoxide dismutase would then act on the $\mathrm{O}_{2}^{-}$ produced as a result of the $\mathrm{TeO}_{3}^{2-}$ reduction. The result of eliminating components of this cascade would severely damage thiol redox. Subsequently, the consequences of tellurite exposure would be the shutting down of cellular processes involved in DNA synthesis, protein synthesis, as well as most reductases.

\section{ACKNOWLEDGEMENTS}

We wish to thank the Medical Research Council of Canada for the funding of this work. R.J.T. thanks Drs Kenneth F. Whelan and Gerard Giordano for useful suggestions and discussions. We also thank Yunfang Hou, Gayathri Meadows, and Gudrun A. Trescher for technical assistance. D.E.T. is a Medical Scientist of the Alberta Heritage Foundation for Medical Research.

\section{REFERENCES}

Ariza, R. R., Cohen, S. P., Bachhawat, N., Levy, S. B. \& Demple, B. (1994). Repressor mutations in the $\operatorname{mar} \mathrm{R} A B$ operon that activate oxidative stress genes and multiple antibiotic resistance in Escherichia coli. J Bacteriol 176, 143-148.

Boyer, H. W. \& Roulland-Dussoix, D. (1969). A complementation analysis of the restriction and modification of DNA in Escherichia coli. J Mol Biol 41, 459-472.

Bradley, D. E. (1985). Detection of tellurite-resistance determinants in IncP plasmids. J Gen Microbiol 131, 3135-3137.

Bradley, D. E., Grewal, K., Taylor, D. E. \& Whelan, J. (1988). Characteristics of RP4 tellurite-resistance transposon Tn521. J Gen Microbiol 134, 2009-2018.

Carlioz, A., Ludwig, M. L., Stallings, W. C., Fee, J. A., Steinman, H. M. \& Touati, D. (1988). Iron superoxide dismutaşe: nucleotide sequence of the gene from Escherichia coli $\mathrm{K} 12$ and correlations with crystal structures. J Biol Chem 263, 1555-1562.

Casadaban, M. J. (1976). Transposition and fusion of the lac genes to selected promoters in Eschericbia coli using bacteriophage lambda and mu. J Mol Biol 104, 541-555.

Figurski, D. H., Pohlman, R. F., Bechhofer, D. H., Prince, A. S. \& Kelton, C. A. (1982). Broad host range plasmid RK2 encodes multiple kil genes potentially lethal to Escherichia coli host cells. Proc Natl Acad Sci USA 79, 1935-1939. 
Ganther, H. E. (1971). Reduction of selenotrisulfide derivative of glutathione to persulfide analog by glutathione reductase. Biochemistry 10, 4089-4098.

Griffith, O. W. \& Meister, A. (1979). Potent and specific inhibitors of glutathione synthesis by buthione sulfoximine ( $S$ - $N$-butyl homocysteine sulfoximine). J Biol Chem 254, 7558-7560.

Hill, S. M., Jobling, M. G., Lloyd, B. H., Strike, P. \& Ritchie, D. A. (1993). Functional expression of the tellurite resistance determinant from the IncHI-2 plasmid pMER610. Mol \& Gen Genet 241, 203-212.

Imlay, J. A. \& Fridovich, I. (1991). Assay of metabolic superoxide production in Escherichia coli. J Biol Chem 266, 6957-6965.

Lloyd-Jones, J., Osborn, A. M., Ritchie, D. A., Strike, P., Hobman, J. L., Brown, N. L. \& Rouch, D. A. (1994). Accumulation and intracellular fate of tellurite in tellurite-resistant Escherichia coli: a model for the mechanism of resistance. FEMS Microbiol Lett 118, $113-120$

Miller, J. F. (1992). A Short Course in Bacterial Genetics. Cold Spring Harbor, NY: Cold Spring Harbor Laboratory.

Moore, W. R., Anderson, M. E., Meister, A., Murata, K. \& Kimura, A. (1989). Increased capacity for glutathione synthesis enhances resistance to radiation in Escherichia coli: a possible model for mammalian cell protection. Proc Natl Acad Sci US A 86, 1461-1464.

Oden, K. L., Gladysheva, T. B. \& Rosen, B. P. (1994). Arsenate reduction mediated by the plasmid-encoded ArsC protein is coupled to glutathione. Mol Microbiol 12, 301-306.

Pansegrau, W., Lanka, E., Barth, P. T., Figurski, D. H., Guiney, D. G., Haas, D., Helinski, D. R., Schwab, H., Stanisich, V. A. \& Thomas, C. M. (1994). Complete nucleotide sequence of Birmingham IncP $\alpha$ plasmids. Compilation and comparative analysis. J Mol Biol 239, 623-663.

Penninckx, M. J. \& Elskens, M. T. (1993). Metabolism and functions of glutathione in micro-organisms. Adv Microb Pbysiol 34, 239-301.

Romero, M. J. M. \& Canada, A. T. (1991). The evaluation of Escberichia coli as a model for oxidant stress in mammalian hepatocytes: role of glutathione. Toxicol Appl Pharmacol 111, 485-495.

Rosner, J. L. \& Slonczewski, J. L. (1994). Dual regulation of ina $A$ by the multiple antibiotic resistance (Mar) and superoxide (SoxRS) stress response systems of Escherichia coli.J Bacteriol 176, 6262-6269.

Salles, B. \& Calsou, P. (1992). Involvement of glutathione in cisplatinum toxicity in Escherichia coli K12. Toxicology 72, 341-350.

Sambrook, J., Fritsch, E. R. \& Maniatis, T. (1989). Molecular Cloning: a Laboratory Manual, 2nd edn. Cold Spring Harbor, NY: Cold Spring Harbor Laboratory.

Taylor, D. E., Walter, E. G., Sherburne, R. \& Bazett-Jones, D. P. (1988). Structure and location of tellurium deposited in Escherichia coli cells harboring tellurite resistance plasmids. J Ultrastruct Mol Struct Res 99, 18-26.
Taylor, D. E., Họu, Y., Turner, R. J. \& Weiner, J. H. (1994). Location of a potassium tellurite resistance operon $(t e h A t e h B)$ within the terminus of Escherichia coli K-12. J Bacteriol 176, 2740-2742.

Thomas, C. M. \& Smith, C. A. (1987). Incompatibility group P plasmids: genetics, evolution, and use in genetic manipulation. Annu Rev Microbiol 41, 77-101.

Tomas, J. M. \& Kay, W. W. (1986). Tellurite susceptibility and nonplasmid-mediated resistance in Eschericbia coli. Antimicrob Agents Chemother 30, 127-131.

Touati, D. (1983). Cloning and mapping of the manganese superoxide dismutase gene (sodA) of Escherichia coli K-12. J Bacteriol 155, 1078-1087.

Turner, R. J., Hou, Y., Weiner, J. H. \& Taylor, D. E. (1992a). The arsenical ATPase efflux pump mediates tellurite resistance. $J$ Bacteriol 174, 3092-3094.

Turner, R. J., Weiner, J. H. \& Taylor, D. E. (1992b). Use of diethyldithiocarbamate for quantitative determination of tellurite uptake by bacteria. Anal Biochem 204, 292-295.

Turner, R. J., Weiner, J. H. \& Taylor, D. E. (1994a). Characterization of the growth inhibition phenotype of the kil Atel $A B$ operon from IncP $\alpha$ plasmid RK2Ter. Biocbem Cell Biol 72, 333-342.

Turner, R. J., Weiner, J.H. \& Taylor, D. E. (1994b). In vivo complementation and site-specific mutagenesis of the tellurite resistance determinant kilAtelAB from IncP $\alpha$ plasmid $\mathrm{RK}_{2} \mathrm{Te}^{\mathrm{r}}$. Microbiology 140, 1319-1326.

Turner, R. J., Weiner, J. H. \& Taylor, D. E. (1995). Neither reduced uptake nor increased efflux is encoded by tellurite resistance determinants expressed in Eschericbia coli. Can J Microbiol 41, 92-98.

Walter, E. G. \& Taylor, D. E. (1989). Comparison of tellurite resistance determinants from the IncP $\alpha$ plasmid $\mathrm{RP}_{4} \mathrm{Te}^{r}$ and the IncHII plasmid pHH1508a. J Bacteriol 171, 2160-2165.

Walter, E. G. \& Taylor, D. E. (1992). Plasmid-mediated resistance to tellurite: expressed and cryptic. Plasmid 27, 52-64.

Walter, E. G., Thomas, C. M., Ibbotson, J.P. \& Taylor, D. E. (1991a). Transcriptional analysis, translational analysis, and sequence of the kil $A$-tellurite resistance region of plasmid $\mathrm{RK}^{2} \mathrm{Te}^{\mathrm{r}} . J$ Bacteriol 173, 1111-1119.

Walter, E. G., Weiner, J. H. \& Taylor, D. E. (1991b). Nucleotide sequence and overexpression of the tellurite resistance determinant from the IncHII plasmid pHH1508a. Gene 101, 1-7.

Wu, J.-Y., Siegel, L. M. \& Kredich, N. M. (1991). High-level expression of Escherichia coli NADPH-sulfite reductase: requirement for a cloned $c y s G$ plasmid to overcome limiting siroheme cofactor. J Bacteriol 173, 325-333.

Received 15 June 1995; revised 15 August 1995; accepted 17 August 1995. 